EPiC Series in Education Science
Volume 1, 2017, Pages 393-401

\title{
PREFABRICATION TECHNIQUE FOR LOW COST HOUSING IN ASSAM
}

\author{
A. Deka ${ }^{1}$, H. Doloi ${ }^{2}$ and R. H. Crawford ${ }^{3}$ \\ $1 \mathrm{PhD}$ student, Smart Villages Lab, The University of Melbourne, \\ ${ }^{2}$ Senior Lecturer, Smart Villages Lab, The University of Melbourne \\ ${ }^{3}$ Associate Professor, Smart Villages Lab, The University of Melbourne name of affiliation \\ arup.deka8@gmail.com
}

\begin{abstract}
The housing Pattern of North Eastern part of India can be categorized in three different types. The old primitive type of housing known as Assam type houses are predominant in the North-eastern region. These are mostly residential houses maximum upto single story. The house is generally made of timber. The vertical Post, roofing are made of wood, bamboo supported biomass wall cladding for wall panels are used. With the passage of time this unique method of construction gained importance and newer technology with the use of brick masonry, R.C coloumn and timber roof are being adopted by the local people. This transfer of technology from generation after generation led to the present housing scenario which can be termed as non engineered houses mainly modular and non modular type of construction and R.C.C structures. These non engineered houses have very low vulnerability and poor comfort. The construction type for these houses are dependent on weathering conditions. Therefore there is an urgent need to provide housing with basic facilities for improving living standards without disturbing the natural resources and creating employment opportunities for the local communities. This research aims to investigate the modernisation of the physical structure, construction processes, use of prefabricated components, composite materials, affordability and sustainability of the housing types in Assam.
\end{abstract}

Keywords: Prefabrication, India, Smart Villages, Rural, Building

\section{INTRODUCTION}

Assam which is located in the North-eastern region of India, Guwahati is the main capital city known as the gateway of North-east. Assam has a population of 3.12 Crores as per census 2011. A significant increase in population has occurred from 2.67 Crores in 2001, leading to a growth rate of $17.07 \%$ in a decade. The present affordable housing provision is inadequate in Assam. The rapid growth of population and modernized culture has resulted in a range of housing demands including cost optimization, safety, time constraint and environmental protection. The current research aims to 
investigate the present housing pattern of Assam, challenges faced by the local construction industry, how the current construction industry may benefit from prefabrication. The housing pattern of Northeast India including Assam are still using the primitive construction methodologies. The typical Assam type house, built in local design with bamboo as wall material and thatch/ backed clay tiles as roof materials is a prominent feature of the housing scenario, especially in rural areas. These houses have a light tin roof and wooden floors that are "highly earthquake resistant", Kaushik, H.B., and Ravindra Babu, K.S. (2012), "Assam-type House", World Housing Encyclopedia Report No. 154, Published by Earthquake Engineering Research Institute (EERI), US and International Association for Earthquake Engineering (IAEE), Japan. The buildings are light, flexible and able to move with the swaying caused by tremors (Kaushik and Babu, 2012). However with the increase in population rate and shortage of land the old Assam type houses have been replaced with multi storied buildings in most parts of Assam. Guwahati the capital city of Assam known as the gateway of Northeast India is experiencing a rapid increase in the number of high rise buildings. Significant improvements to the Assam construction industry are needed to ensure that this expansion leads to safe, efficient, affordable and sustainable housing solutions. Government of India has already launched a Mission/scheme/canvas Pradhan Mantri Awas yojna (Housing for all) to facilitate adoptation of modern and innovative better building materials and green technologies for faster and quality construction of housing. But despite concerted efforts at various levels, the housing problem is not yet solved to the extent required especially in Assam. In Assam construction components are installed and made on site. Installation of the building services is quite rudimentary. Thus research and standardization of non-conventional materials with available natural material such as bamboo, possible in the form of bamboo reinforced fibre panels could be a useful prefabrication technique. Such solutions coupled with advocacy and effective design methodology may lead to broader social acceptance. prefabricated construction could be a favourable solution in Assam providing an impetus to the present construction industry, assisting in improving quality standard of the overall workmanship of housing construction. A thorough literature review is being carried out keeping in view to understand the prefabrication construction in the world.

Prefabrication is the method of construction where both cost and time optimization can be achieved. Prefabrication is the practice of assembling component parts of a structure in the factory or a temporary plant established on the nearby site. These component parts are transported, assembled and erected on the construction site. This is a promising innovation and eco- friendly (Brandon \& Hampson, 2004).Prefabricated construction can be carried out in poor weather conditions reducing the wasted time and materials since component parts are factory made and on site equipment such as formwork and scaffolding can be largely eliminated. prefabrication is an offsite manufacturing process that takes place at a specialized facility in which various materials and building systems are joined to form a component part of a larger final installation (Gibb 1999). An overall aim of the current research is to acquire knowledge, achieving flexibility and ensure the need of development of present housing scenario over traditional housing system.

The prefabricated housing system and its different developments are not new. The first prefab related house was built in the 1600s in the Massachusetts colony. The process did not become popular until centuries later when several companies began to develop house kits, which contained numbered, precut parts that individuals could put together themselves. The Michigan-based Aladdin Company began to sell these kits by catalog in 1906. Two years later, Sears, Roebuck and Company became known for selling the kits. From 1914 Prefabricated building approaches helped address British and European housing shortages during the post war era. In the 1990's Japan's automated production lines began to produce high quality prefabricated houses in record time. There are numerous examples of buildings that were manufactured in locations such as London, Glasgow, Liverpool in the UK, or Singapore and Hong Kong in Asia, then packaged up on to ships that carried the goods to other countries where they were then assembled. An example of Australian colonial prefabricated buildings is Geelong's celebrated home Corio Villa, which was manufactured by 
Robertson \& Lister of Glasgow, Scotland around1854-5, then erected in Geelong circa 1855-6. Haas et al. 2000,) stated the modularization technique "the preconstruction of a complete system away from the job site that is then transported to the site. The modules are large in size and possibly may need to be broken down in to several smaller pieces for transport". Work is done at an offsite location for increased construction speed and quality.

Hartley and Blagden (2007) stated Prefabricated components are simple building blocks that usually involve a single building trade. The vast majority of buildings constructed today use some form of prefabrication. Applications include timber framed panels, precast panels, steel framed panels, structural insulated panels (SIP's), building envelope/façade systems, composite panels, precast cladding, Light Steel Frame Building Systems, pre-cast structural elements, insulating concrete formwork. A broad range of materials can and has been used in prefabricated construction. This include typical construction materials such as steel, concrete and more un-conventional materials. For example Mansur and Aziz (1982) studied jute fibre reinforced composite and tested it in direct tension, flexure and axial compression impact. This study has shown the feasibility of jute as a low cost housing material for roof and wall panel construction. Mathur (2006) has also reported development of building materials with natural resources like jute fibre, coconut coir etc. He also suggested about the use of natural fibre as a composite material for low cost housing. Staiger and Tucker (2008) concluded that specific tensile strength of natural fibre are similar to those of glass fibre. Palanichamy, M.S. et al, (2002) developed prefabrication techniques for residential buildings using a series of pre cast units such as precast R.C.C planks, precast R.C joists are considered for flooring and roofing system. precast columns are also used and the cost analysis was being made. It showed the increase in cost is mainly due to erection charges. Clyde Zhengdao Li, et al, (2015) witnessed serious housing demand in Hong Kong and made to facilitate the development of prefabrication using technologies such as building information modelling, help of information technology tools and corresponding management strategies for the development of housing pattern in Hong Kong. Dineshkumar, N. and Kathirvel, p. 2015 studied the present construction Industry in India and compared the conventional method of construction with the prefab construction method of construction and found cost differences between this two methods. Construction using Prefabrication was tend to be much more expensive than the conventional method in case of individual residential buildings. However the author stated that prefabricated construction is easy to work and reduces project duration. Zhao and Rifat (2016) emphasised for promoting Prefabrication technique seeking for low cost technique using sustainable recycled material such as rammed earth, blast furnace sag, fly ash, straw, use of modular design and advance machinery technique with intelligent computer aided design. Despite there is so much of development since 1960 to 2010 the adoption in prefabricated housing present is not at per. The current paper aims at understanding the shortfalls by the systematic review of the world literature.

\subsection{METHOD USED}

The literature review was primarily done by systematically using online searches with over millions of articles from journal, conferences, publications related to construction in housing. The scope of the search considered recent research published since 1990s and onwards as per the terms shown in the Figure 1. 


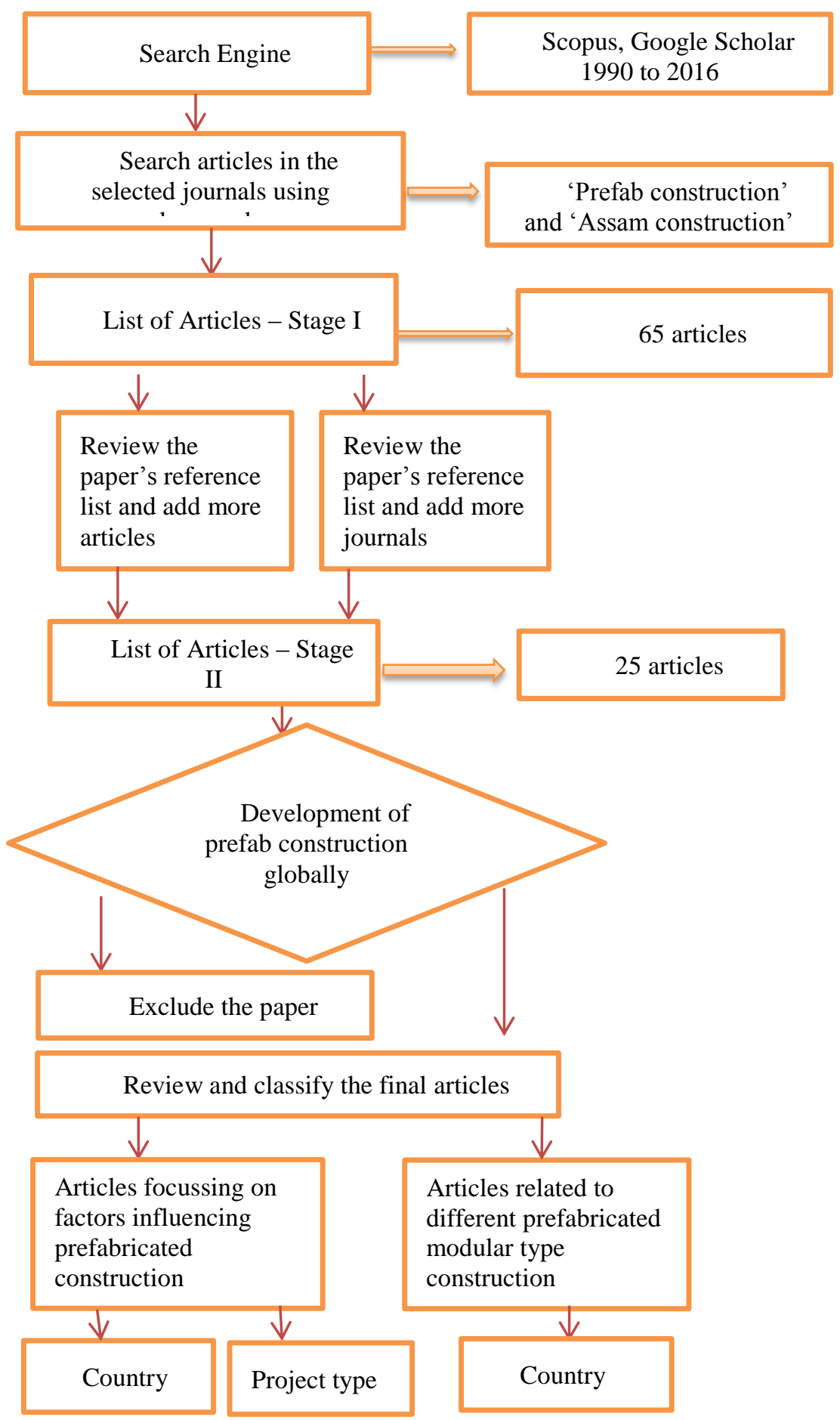

Figure 1: Systematic review of the literature in world context 


\subsection{ASSAM CONSTRUCTION INDUSTRY AND PREFABRICATION}

Assam has the largest economy of the Northeast India. The construction sector is the secondlargest economic segment after agriculture. The Northeast is not far behind the rest of the country when it comes to growth in the real estate sector. Assam is fast emerging as an investment hotspot with a growing demand for real estate resulting in huge expansion in both commercial and residential complexes. Guwahati the capital of Assam in the recent years witnessed a sharp increase in the demand for flats, both for residential and commercial purposes whereas in other parts of Assam the demand is greater for private housing construction. However the Real Estate sector of Assam is failing to keep pace with recent housing demands because of its inability to adapt to recent development and technology in the construction fields. The construction of Assam type house is still towards on old and primitive technology. While the Assam type houses are well suited in the state of Assam from the climatic and affordability perspectives, these units could benefit across a number of fronts. Modernisation of the physical structure, construction processes, use of prefabricated units, composite materials, affordability, sustainability etc are all areas need to be addressed. Despite concerted efforts at various levels housing problems are not yet solved to the extent of requirement especially in the Northeast. With the Foreign Direct Investment policy coming into effect and the North East Industrial policy offering competitive support for Assam with cheap land and labour there has never been a more critical time for the development of regulatory mechanism along with improvement to the construction industry to help support upcoming demands.

\subsection{BARRIERS AND CHALLENGES IN ASSAM}

There are numbers of issues and challenges facing in Assam many of which have an influence on the ability to provide affordable, sustainable housing.

\section{Geographical location}

Assam which is situated in the isolated part of India has abundant natural resources viz. oil, tea, minerals, dense forest. It shares its boundaries with Bhutan, Bangladesh and surrounded by the states of Arunachal Pradesh, Nagaland, Manipur, Mizoram, Meghalaya and Tripura. Because of its isolated location surrounded by hilly terrain, river and dense forest the cost of construction is generally higher.

\section{Day by day increase in population}

The rapid growth of population in Assam causes stress on infrastructure and basic services. As per the census 2011 the growth rate of population in this decade was 17.07\%. As such with that increasing number of populations will create unemployment and poverty.

\section{Infrastructure and road connectivity}

Assam is lacking an effective transportation system and rural road connectivity through its neighbouring states because of its hilly terrain and some local organisation, which are hindering the progress of Assam and the Northeast. Without road connectivity and proper modes of transportation industrial establishment is hard to achieve. In the recent years government has taken measures to improve the connectivity by launching various schemes for the roads, railways and inland water communication. 


\section{Natural disasters}

Assam is prone to natural flood every year, major of its land is eroded by the river Brahmaputra and its tributaries resulting in major setback in the development of the state, its productions and income. Because of the natural disasters speedy implementation of construction project becomes difficult since during monsoon on site construction work can not be carried out because of heavy rains.

\section{Data based Information technology}

In Assam the information regarding housing numbers and their present conditions are not adequate. Innovative Information technology with data based system needs to be monitored and applied.

\subsection{Lack of skilled personnel}

In Assam there is a shortage of skilled personnel. Most of the personnel are unskilled and are from different states. Assam needs to hire skilled technicians from outside for some specific jobs which in turn increases the project cost and makes the project lengthy. Skilled labour with proper training would result a more sustainable construction industry.

\section{Technical Advancement}

Assam is still suffering from lack of technical advancement. It still relies on vernacular practices in construction industries and many other sectors. There has been a reluctance to change.

\section{Cost and Time}

The another challenges that the construction industry faces is time management. Most of the projects are not time bound, which indirectly affects the cost. Moreover North-eastern region generally experiences heavy rainfall during monsoon so the actual working time for construction is generally restricted to $8-9$ months in a year.

\section{Real estate developers:}

Here the real estate developers are mainly builders, architects, engineers and contractors. The adaptation of prefabricated housing solely depends on the willingness of the builders and their acceptance.

\section{Cost and investment return:}

High initial cost involvement for the manufacturing processes is one of the barriers for prefabricated housing. The small builders keep themselves refrained from the prefabricated construction housing because of high initial cost additionally there is no innovative technique on prefabricated housing for these small builders to adopt this system.

\section{Lack of manufacturers :}

Currently there is a small prefabricated housing manufacturer in Assam albeit these units are out sourced. The construction sector needs to train construction professionals in the area of prefabrication.

\section{Users acceptance :}

The acceptance of the users in prefabricated housing with proper robust flexible technique by understanding their sentiments.

\section{Government policy :}


Government must formulate some policies and legislation to influence prefabricated housing and open direct competition in prefabricated housing with the traditional one.

Geological stratum_ : The sub soil property of the geological stratum plays a important role in prefabricated construction since Assam falls in highly seismic zone, zone V.

Design codes_: There are no codes guiding the use of prefabricated houses.

Material transport_: The logistics of delivering the housing components at the site needs to be addressed especially for prefabricated units.

Weathering condition : The weathering conditions delays the construction time of the project.

\subsection{DRIVERS IN ADOPTING PREFABRICATED CONSTRUCTION}

Cost and time : Reducing cost and time of construction is the potential key for adaptation of prefabricated construction.

Real estate developers : Simplicity of connections, with different ranges of sizes and varities of available structural component may help in adopting prefabricated housing.

Workforce : With the existing construction industry the same workforce can be trained for prefabricated housing which may in turn drive them in entrepreneurship creating employment option.

Present demand of housings : with the present demand for residential housing and Government scheme it is becoming necessary for an alternative solution to housing in time.

Expansion of the city_: The main cities in Assam are expanding gradually because of traffic regulatories and land reform policies, this areas needs to be develoed with proper infrastructural policies.

Present modern trend : The present modern trend and culture demands high rise buildings with modern architectural design and safety.

Government policy : The present Central Government focusing largely in the infrastructure development of the north eastern region through "Act East Policy", therefore there is a huge demand and development likely to take place in all front.

Climatic effect_ : Assam experiences high monsoon, due to which actual on site working days greatly reduced causing delays in completion time of the project. 


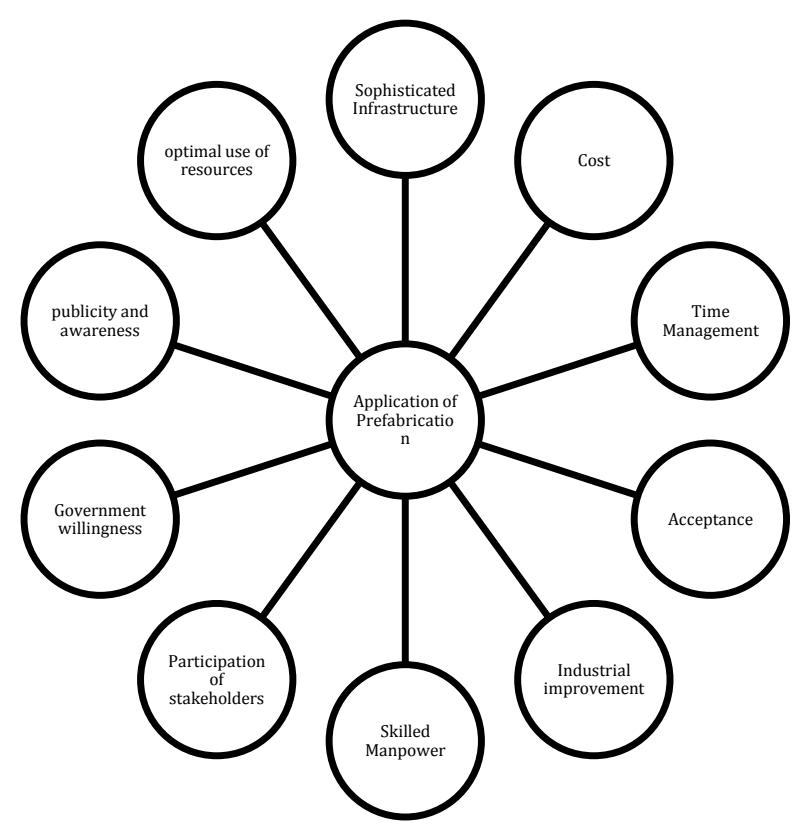

Figure 2: key elements for the prefabrication

\section{DISCUSSION AND CONCLUSION}

Assam has huge scope for modernization of its Construction industry. Prefabrication which is a knowledge based technology still not broadly adopted in India as per the development since 1950. The key issue for promoting prefabrication from the published barriers and constraints are the lack of regulatory body and policies favouring the implementation of prefabricated technology. The most direct influence in adopting prefab technology is cost. However the success of prefabrication technology as a low cost construction technique is the identification of local available materials such as bamboo, rice husk, fly ash etc. that can be used as a part of appropriate structural components with proper design. More over the data base system for the present housing numbers is not adequate. Some innovative information technologies regarding the present housing scenario and available housing needs to be carried out as a database management system. There must be a proper integration and coordination between the builders, suppliers and engineers as an outcome for future development. Prefabricated could be potential benefit for Assam in terms improving the local industry, employment opportunities for the local people by providing necessary training thereby developing skilled personal required to be associated with prefabricated construction in Assam or in different parts of India. Housing comfort can be provided as per requirement with better quality and durable factory products. Government also needs to adopt some policies to facilitate the prefabrication approach in terms of incentives or subsidy to attract public sector/private sector for enhancing the prefabrication technology. Future scope may consider structural design consideration of different component parts, safety aspects and the use of locally available materials for creating more sustainable solution. Modernisation of the physical structure, construction processes, use of prefabricated units, composite materials, affordability, sustainability etc are to be examined in such housing units. This paper aims to provide an overview of the present construction industry in Assam, and consider how prefabrication could be a useful construction methodology for North East India. It also aims at adopting 
prefabricated construction for sustainable and affordable housing in Assam and their challenges and benefit in case of Assam construction industry

\section{REFERENCES}

Clyde Zhengdao Li, et al, (2015) "Current housing situation and need for prefabrication housing production in Hong Kong" The Australasian universities Building Educators association conference; held in Sydney 2015, Australia in association with AUBEA, the university of technology Sydney and university of western Sydney.

Dineshkumar, N. Kathirvel, P. 2015 " Comparative study of the Prefabrication Construction with cast in situ construction for residential buildings" issue 4, April 2015. www. ijiset. com ISSN 2348 $-7968$

Gibb, A. (1999), "Off-Site Fabrication: Prefabrication, Pre-assembly and Modularization" John Wiley \& Sons, 27 Oct. 1999

Hartley, A. and Blagden, A. (2007), "Current Practices and Future Potential in Modern Methods of Construction" WAS003-001: Full Final Report, Oxon: Waste \& Resourcesn Action Programme. IS 4326 Earthquake Resistant Design and Construction of Materials, 1993, Building Materials and Technology Promotion Council

Mansur M, Aziz M. (1982), "A study of jute fibre reinforced cement composites”. Int J Cem Comp Lightweight Concrete :75-82. doi: 10.1016/0262 5075(82)90011-2.

Mathur, V. K. (2006) Composite Materials from Local Resources. Construction and Building Materials,20,470-477. http://dx.doi.org/10.1016/j.conbuildmat.2005.01.031

Palanichamy, M.S, Muthuramu, K.L, Jeyakumar, G (2002) "Prefabrication Technique for residential building"

Staiger M. P., Tucker N, (2008) "Natural-fibre composites in structural applications", Properties and Performance of Natural-Fibre Composites, Pages 269-300

Xudong Zhao and Saffa rifat (2016) "Prefabrication in House construction" 